\title{
EL PAISAJE TARDÍO DEL VALLE DE HUALFÍN: UNA RECONS- TRUCCIÓN ARQUEOLÓGICA DESDE LOS POBLADOS PROTEGIDOS
}

\author{
THE LATE LANDSCAPE IN HUALFÍN VALLEY: AN \\ ARCHAEOLOGICAL RECONSTRUCTION FROM \\ PROTECTED VILLAGES
}

\author{
Federico Wynveldt ${ }^{1}$, Bárbara Balesta ${ }^{2}$ y María Emilia Iucci ${ }^{3}$ \\ 1 CONICET. Laboratorio de Análisis Cerámico, Facultad de Ciencias Naturales y Museo, UNLP. \\ E-mail: wynveldtf@fcnym.unlp.edu.ar \\ 2 Laboratorio de Análisis Cerámico, Facultad de Ciencias Naturales y Museo, UNLP. \\ E-mail: bbalesta@ciudad.com.ar \\ 3 Laboratorio de Análisis Cerámico, Facultad de Ciencias Naturales y Museo, UNLP. \\ E-mail: emiliaiucci@yahoo.com.ar
}

Presentado el: 15/10/2012 - Aceptado el: 05/07/2013

\begin{abstract}
Resumen
En este artículo se presenta una perspectiva relacional del paisaje y se analiza una serie de sitios arqueológicos (que hemos denominado poblados protegidos por hallarse emplazados sobre lomadas o cerros con diferentes grados de accesibilidad) de momentos tardíos del Valle de Hualfín (Belén, Catamarca), considerando ciertos indicadores de la dimensión espacial como emplazamiento, topografía, barreras para el acceso, configuración espacial y campo visual. Los resultados indican que estos sitios presentan importantes diferencias (de grado y de calidad) en casi todas las variables consideradas. Por otra parte, el análisis de las líneas de visión entre los sitios muestra un contraste importante entre el Sector Sur del valle, totalmente integrado por relaciones directas de intervisibilidad, y el Sector Norte, mucho más fragmentado, sin líneas visuales directas entre poblados. A partir de estos resultados espaciales, se proponen algunas líneas de análisis en relación con aspectos de la dimensión temporal (fechados radiocarbónicos) y de los objetos materiales, particularmente la distribución de obsidiana y vasijas de distintos tipos cerámicos. Como principal conjetura se sostiene que la diferenciación entre los sectores Norte y Sur podría ser un reflejo de distintos grados de integración regional hacia el interior del valle durante el siglo XV, y tal vez de diferentes respuestas socio-politicas en relación a los vínculos con grupos tanto locales como foráneos.
\end{abstract}

Palabras clave: Poblados protegidos; Valle de Hualfin; Período Tardío; Dimensión espacial del paisaje 


\begin{abstract}
In this paper we present a relational landscape perspective and we analyze a set of archaeological sites (that we called protected villages because of their emplacement on top of hills with different grade of accessibility) for late moments in Hualfin Valley (Belén, Catamarca), considering archaeological indicators belonging to spatial dimension, as placement, topography, access barriers, spatial configuration and visual scope. Results indicate that these villages have important differences (in grade and quality) between them in most variables. Otherwise, lines of vision show an important contrast between Southern Sector, absolutely integrated by direct relations, and Northern Sector, fragmented, with no direct visual lines between the villages. As from these results, we propose some lines to analyze related with aspects about temporal dimension (radiocarbon dates) and material objects dimension, particularly obsidian and different pottery styles distribution. We hypothesize that differences between Northern and Southern sectors could be a product of different grades of regional integration in the valley during fifteenth century, and maybe diverse socio-political responses dealing with the relations with local or foreign groups.
\end{abstract}

Keywords: Protected villages; Hualfin Valley; Late Period; Landscape

\title{
Introducción
}

El Valle de Hualfín (Depto. de Belén, Prov. de Catamarca) ha tenido una larga tradición en cuanto a las investigaciones sobre las sociedades agro-alfareras prehispánicas. Ya hacia fines del siglo XIX comenzaron a estudiarse materiales que luego fueron adscriptos temporalmente al Período Tardío o de Desarrollos Regionales (1000-1480 AD). Sin embargo, por distintas razones (científicas e históricas) fue recién Rex González (1955) quien asoció por primera vez determinados ítems materiales con sitios de ocupación tardíos concretos, en el marco de su secuencia relativa conformada por tres fases para la Cultura Belén, posteriormente cuestionadas a la luz de la nueva información arquitectónica y radiocarbónica (Sempé 1981; Wynveldt 2009; Wynveldt e Iucci 2013).

Luego, otros aportes pusieron el foco principalmente en la caracterización del patrón de asentamiento para el Período Tardío, dentro de un modelo geopolítico en el que el Valle de Hualfín constituía el núcleo hegemónico de una organización que llegaría, complejización mediante, a conformar un señorío (Sempé 1999). Según Sempé, el patrón de asentamiento Belén se caracteriza por una jerarquía de sitios -pueblos aglomerados, pueblos abiertos (característicos del Valle de Abaucán) y aldeas entre sistemas de andenes de cultivo-, que reflejaría la complejidad de la organización social de los grupos. En cuanto a los pueblos aglomerados en particular, la autora señala en sus descripciones importantes diferencias en la configuración espacial de los distintos sitios, y su explicación se remite al proceso de complejización esbozado por González (1955) que se inicia con el patrón simple y abierto de la fase I, pasando luego al emplazamiento en lomadas protegidas con recintos aislados en la fase II, para finalmente ubicar de manera implícita a los sitios de mayor complejidad hacia fines de la fase II y en la fase III.

En los últimos años las investigaciones sobre el tardío en la región crecieron notablemente, tanto en el número como en la diversidad y la especificidad de las temáticas abordadas, generándose numerosos aportes acerca de los procesos socio-políticos desarrollados en el valle, sobre todo en lo que respecta a los probables conflictos intergrupales -que parecen haber inundado el área andina para esos momentos-, a las causas del abandono de los 
sitios y a los efectos de la conquista inkaica. Estos trabajos se sustentan teóricamente en el concepto de paisaje como marco general para la reconstrucción de la historia regional, a partir del análisis de todos los indicadores arqueológicos disponibles.

En este artículo nos proponemos analizar una serie de sitios que presentan grados variables de protección, desde murallas defensivas hasta un emplazamiento en altura con diferentes dificultades de acceso, considerando ciertos indicadores arqueológicos de la dimensión espacial del paisaje: emplazamiento, topografía, barreras para el acceso, configuración espacial y campo visual. De esta manera se intenta reconstruir qué tipo de relaciones existieron entre estos poblados en cuanto a los aspectos espaciales considerados. Finalmente, presentamos diferentes líneas de análisis referidas a las restantes dimensiones que conforman nuestra propuesta paisajística -la dimensión de los objetos materiales y la dimensión temporal-, exponiendo algunas de las ideas que sostenemos con respecto a la configuración del paisaje socio-político tardío regional.

\section{El paisaje relacional y sus dimensiones}

El concepto de paisaje como marco de referencia para el estudio de las relaciones entre el ser humano y su ambiente es hoy día una herramienta ampliamente aceptada en arqueología. Sin embargo, desde la aparición del término en los trabajos de los geógrafos humanos del siglo XIX, hasta su posterior diversificación, producto de la incorporación de elementos, no sólo de la geografía, sino también de la ecología, la historia, la arquitectura, la antropología y la arqueología, el paisaje ha sido abordado desde distintas corrientes teóricas y metodológicas. En la raíz de esos antagonismos muchas veces puede notarse una diferencia fundamental en otra noción clave para la definición del paisaje: el espacio.

En las ciencias sociales la noción de espacio ha sido utilizada tradicionalmente desde dos perspectivas muy diferentes. Una de ellas es la posición objetivista, para la cual el espacio consiste en una categoría absoluta, una clase única e inmutable de objeto, que es empíricamente imposible de comprender, y que sólo se puede inferir a través de fenómenos observables. Esta idea, como sostiene Criado Boado (1991) se corresponde con la concepción de espacio capitalista y moderno, según la cual el espacio es entendido como un problema natural, geográfico, o bien como un mero lugar de residencia y expansión de un pueblo o Estado, reduciéndose a la dimensión de territorio. El paisaje como era entendido en la geografía humana clásica tenía fuertes connotaciones visuales, estéticas y morales, alejadas de los preceptos ligados a las investigaciones cuantitativas mas cientificistas, que buscaban resultados más precisos y objetivos. Desde esta perspectiva objetivista entonces, el término paisaje fue dejado a un lado o empleado como sinónimo de medio ambiente o de patrón de asentamiento (Anschuetz et al. 2001).

Por otro lado, las posturas subjetivistas sobre el espacio incorporaron otras dimensiones más allá de la estrictamente material, analizándolo en función de los lazos entre diferencias culturales y formales y explicando cómo distintos pueblos construyen diversas formas de vida. Diferentes perspectivas dentro de esta línea, como los enfoques cualitativos (Tuan 1977) y sociohistóricos (Cosgrove 1984), y los análisis sobre el ambiente construido (Rapoport 1978), llevaron a retomar la idea del paisaje como organizador de la interacción espacial, como mecanismo para recordar las interacciones pasadas y para informar y legitimar las relaciones presentes. También se desarrolló una corriente neo-marxista para la cual los paisajes están determinados por el interjuego de fuerzas de producción, relaciones 
de producción, estructuras y procesos de la naturaleza históricamente contingentes, y la valoración y cognición humanas de las estructuras y procesos naturales (Patterson 1994). Los teóricos posmodernos han ofrecido una definición alternativa de paisaje, como un ambiente socialmente construido, en el cual los seres humanos forman y reforman sus relaciones entre sí y con el mundo natural. La naturaleza no es para ellos un mundo aparte, sino un mundo constituido social y significativamente (Jarvis 1998).

Sin embargo, estas posiciones subjetivistas no aportaron herramientas para determinar de qué manera los espacios son imbuidos de significado, ni tomaron en cuenta la organización social de la producción y los aspectos económicos involucrados en la construcción de esos espacios, además de que relegaron el estudio de la materialidad del espacio y su capacidad para significar, restringir, direccionar y ordenar relaciones físicas y sociales, ignorando el papel que desempeña el poder en la construcción del espacio social (Smith 2003).

Más allá de la oposición entre las perspectivas objetivistas y subjetivistas, Zedeño (2000) sostiene que la debilidad del concepto de paisaje radica en el significado perceptivo, metafórico, de sentido común, que parece evocar un entendimiento intercultural sobre una imagen determinada del mundo, corriéndose el riesgo de imponer una noción sin identificar explícita y sistemáticamente el criterio que guió la formulación de tal imagen. En base a esta crítica, Zedeño desarrolla su propia postura a partir de la definición de los conceptos de espacio, lugar, landmark o punto de referencia y, finalmente, paisaje, concebido como una red (no simplemente una suma) de puntos de referencia que se vinculan progresivamente entre sí, a través de múltiples interacciones entre la gente y entre la gente y los recursos. Desde esta posición, el paisaje está caracterizado por tres dimensiones básicas: la formal, consistente en las características físicas de los puntos de referencia; la relacional, referida a los lazos interactivos (económicos, sociales, rituales) que a través del movimiento de la gente conectan puntos de referencia entre sí; y la histórica, es decir, los lazos secuenciales que resultan de los usos sucesivos de los lugares. A partir de esta base teórica, Zedeño propone una "caracterización contextual del paisaje" que comienza en un punto de referencia específico, y progresivamente reconstruye lazos formales, relacionales e históricos con otros puntos de referencia. La estrategia consiste en expandir los lazos en todas las direcciones posibles o realizables, examinando la red de puntos ligados potencialmente para descubrir la lógica detrás de un paisaje particular.

Smith (2003) por su parte, define al paisaje como una producción histórica de lazos que unen espacios (como formas que delimitan la experiencia física), lugares (como estéticas geográficas que unen significados con localizaciones) y representaciones (como cartografías imaginadas de mundos posibles). El espacio, definido como las relaciones entre cuerpos, formas y elementos, es un producto de relaciones entre actores que se entrecruzan, negocian y compiten, con capacidades prácticas diversas para transformar estas relaciones. Por lo tanto, si las relaciones espaciales se establecen dentro de prácticas sociales, nuestras preguntas deben ir más allá de la descripción formal, para entender el espacio físico del ambiente, el espacio percibido por los sentidos y el espacio representado por la imaginación, como dominios que se conectan dentro de la vida social. Mientras los lugares se refieren a localizaciones específicas, restringidas en extensión, los paisajes son más abarcativos, tanto espacial como temporalmente, comprendiendo no sólo lugares y momentos específicos sino también las tensiones (físicas, estéticas y representacionales) entre ellos. Los paisajes juntan lugares para presentar visiones coherentes del mundo. En términos de Smith, el concepto de 
paisaje le da unidad a la experiencia, la percepción y la imaginación en la práctica espacial. Por otro lado, los paisajes son necesariamente paisajes políticos, no solamente porque son expresiones de organización política, sino porque son en sí mismos orden político; ninguna noción de paisaje puede sostener un concepto apolítico de espacio.

Analíticamente, Smith considera entonces tres dimensiones prácticas del paisaje: el espacio físico del ambiente, el espacio percibido de los sentidos y el espacio representacional de la imaginación, como dominios interconectados de la vida social. La experiencia espacial (prácticas materiales) describe el flujo de cuerpos y cosas a través del espacio físico. Comprende no sólo el movimiento a través de espacios terminados sino también las técnicas (o procedimientos) y tecnologías (o conocimientos) de la construcción. La percepción espacial describe la interacción sensorial entre actores y espacios físicos. Es un espacio de signos, señales, claves y códigos, que intenta superar a las teorías subjetivistas de la comunicación aclarando que ésta no se debe reducir a un sistema de codificaciones y decodificaciones. Considera al espacio evocativo como un dominio analítico en el que los términos afectivos describen interacciones entre los seres humanos y su ambiente, superando a las tendencias fenomenológicas. Mientras que la percepción espacial se mantiene ligada a la forma, la imaginación espacial surge enteramente en los discursos sobre el espacio, como los correspondientes al dominio analítico de las representaciones, desde mapas y paisajes pictóricos a la teoría y la filosofía espacial (Smith 2003).

Ingold (2000) a su vez, incorporando también las ideas de la teoría de la práctica, discutiendo las nociones de experiencia y percepción del ambiente, y adoptando la "perspectiva del habitar" (the dwelling perspective), se enfoca particularmente en la temporalidad del paisaje, como una forma de ir más allá de la oposición entre la visión naturalista del paisaje como el telón de fondo externo y neutral de las actividades humanas, y la visión culturalista de que todo paisaje es un orden cognitivo o simbólico particular del espacio. Partiendo de la concepción del organismo-persona inmerso en un ambiente como una condición ineludible de la existencia, Ingold sostiene que el paisaje se configura como un registro duradero (y un testimonio) de las vidas y trabajos de generaciones pasadas que lo han habitado, dejando allí algo de ellos mismos. Su idea de paisaje se aparta también de los conceptos de tierra, naturaleza, espacio y ambiente, proponiendo la noción alternativa de taskscape para denotar los patrones de actividades propias del habitar. De acuerdo con su perspectiva, las formas que la gente construye (en su imaginación o en la superficie terrestre), al igual que otras estructuras ambientales, nunca están completas, sino que se encuentran continuamente en construcción, y tienen historias de vida que las vinculan con sus habitantes humanos y no humanos.

De esta manera, las propuestas de Zedeño, Smith e Ingold se basan en un concepto de paisaje que se construye a partir de lazos que unen objetos progresivamente, o puntos de referencia, lugares y secuencias, experiencias, percepciones y representaciones, ambientes, tiempo y formas de habitar. El espacio a su vez también es concebido como un conjunto de relaciones que se establecen dentro de prácticas sociales, entre cuerpos, formas y elementos, donde la política juega un papel fundamental. A partir de este conjunto de ideas que adoptamos como bases críticas y constructivas, edificamos un marco conceptual para abordar el estudio del paisaje tardío del Valle de Hualfín desde una perspectiva relacional, teniendo en cuenta tres dimensiones operativas: la dimensión espacial, la dimensión de los objetos materiales y la dimensión temporal. 
La dimensión espacial se vincula con los aspectos ligados a la experiencia y la percepción espaciales. En lo que refiere a la experiencia espacial se diferencian las prácticas vinculadas con la construcción del espacio físico de aquellas que atañen al flujo de cuerpos a través del mismo ${ }^{1}$. En relación a la percepción espacial, interesa particularmente indagar en aspectos tales como los límites físicos (como reflejo de límites conceptuales), los campos visuales, vinculados al control del entorno y la defensibilidad, y la proxémica, dirigida al análisis de la interacción sensorial entre actores y espacios físicos en función de las distancias que existen entre las estructuras en un espacio construido.

La dimensión de los objetos materiales aborda el estudio de la cultura material, particularmente de los objetos "muebles" hallados en el registro arqueológico, y de su relación con las personas. Si consideramos que, como sostiene Smith (2003), el espacio es constitutivo de lo social, la ubicación de cada objeto en su lugar es relevante para la interpretación de la vida social. Finalmente, la dimensión temporal tiene en cuenta el tiempo como una variable compleja, no sólo referida al tiempo cronológico que como arqueólogos representamos en su sentido "objetivo" y lineal, sino también al tiempo práctico, es decir, aquel vinculado al uso de los momentos del día, de las estaciones climáticas, del movimiento solar, de los recorridos medidos en jornadas, etc.

Las tres dimensiones buscan incluir todos los aspectos del registro arqueológico para reconstruir la red de relaciones propia del paisaje tardío, siempre considerando el aspecto político como elemento fundamental en su configuración. Por otra parte, no debemos obviar la artificialidad de la división analítica del paisaje en las dimensiones consideradas. Estas se superponen en muchos aspectos, y por lo tanto, no son excluyentes entre sí. Teniendo en cuenta estas consideraciones, que nos revelan la complejidad de la trama de relaciones por reconstruir, nuestra intención es integrar paulatinamente las tres dimensiones en una propuesta interpretativa y relacional acerca del paisaje tardío del Valle de Hualfín.

\section{Aspectos metodológicos para el análisis del paisaje arqueológico}

Como mencionamos anteriormente, en este trabajo nos centraremos únicamente en algunos aspectos de la dimensión espacial; sin embargo, con el objeto de presentar el conjunto total de nuestra propuesta expondremos también los lineamientos metodológicos para el análisis de la dimensión de los objetos materiales y de la dimensión temporal, que en un futuro serán objeto de investigaciones más profundas.

En el análisis de la dimensión espacial se consideran los siguientes aspectos²:

- Emplazamiento del sitio y características del entorno;

- Topografía: altura, superficie y forma del relieve;

- Barreras para el acceso: identificación de barreras naturales y/o artificiales;

- Características de los recintos y otras estructuras arquitectónicas: ubicación, número y características particulares (superficie, tipos de pirca, accesos, pasillos, materiales, comunicación, técnicas constructivas), y configuración de los sectores construidos;

- Límites: un límite físico observado en el registro arqueológico puede ser considerado como simbólico de una barrera conceptual entre dos lugares o cualidades;

- Campo visual: entre sectores intrasitio, del entorno inmediato y del entorno general; análisis de la visibilidad entre los sitios. 
- Relaciones entre los sitios a través del terreno: incluye el análisis de los potenciales caminos que pudieron vincular diferentes puntos de referencia en la región.

El estudio de estos indicadores incluye, por un lado, el registro detallado en el terreno de todos los rasgos mencionados, y por el otro, el análisis de imágenes satelitales para establecer distancias entre poblados, campos de cultivo y/o fuentes de agua, aspectos topográficos generales, puntos de intervisibilidad y determinación de probables caminos entre localidades, brindando además la posibilidad de detectar nuevos sitios, entre otros aportes.

En cuanto al análisis de la dimensión de los objetos materiales la propuesta incorpora la clasificación de los materiales recuperados o analizados (de superficie, de excavación, de colección); la reconstrucción de los contextos arqueológicos (ubicación relativa, depositación, identificación de los procesos postdepositacionales); la descripción de los objetos materiales (calidad, cantidad, manufactura, conservación); el análisis de la distribución de los objetos y sus rasgos a nivel local y regional; la determinación de procedencias (fuentes de aprovisionamiento de arcillas, pigmentos, material lítico, inclusiones no plásticas en la cerámica); etc.

En relación a la dimensión temporal se propone, como adelantamos, analizar por un lado el tiempo cronológico a partir de la consideración de indicadores que proporcionen información sobre la sincronía y diacronía de las construcciones, ocupaciones y abandonos de los sitios arqueológicos, y de todo tipo de objetos y eventos. Serán de utilidad entonces las cronologías relativas -básicamente, la asociación de tipos cerámicos y la identificación de elementos arquitectónicos diagnósticos- y absolutas (fechados radiocarbónicos), procurando identificar momentos constructivos y diferentes ocupaciones y abandonos. Por otra parte, el análisis del tiempo práctico involucrará todo el conocimiento que pueda vincularse con el uso del tiempo, como pueden ser los aspectos climatológicos, el análisis de las distancias y tiempos de recorrido entre los diferentes sitios, el estudio de las variaciones estacionales y de la disponibilidad de diferentes recursos como el agua, los vegetales y los animales, la vinculación entre el emplazamiento o la configuración espacial de los sitios y la trayectoria solar, etc.

\section{Los sitios protegidos tardíos del Valle de Hualfín}

El Valle de Hualfín presenta una innumerable cantidad de sitios arqueológicos que desde un primer acercamiento se identifican como "tardíos" en un sentido amplio, es decir, pertenecientes al período que se desarrolló desde los momentos inmediatamente anteriores a la conquista inkaica hasta los primeros años de la conquista española. Tal adscripción se realiza generalmente a partir del hallazgo de cerámica Belén u otros tipos tardíos en superficie. Entre estos múltiples yacimientos existe una importante diversidad que incluye variedad de entierros (directos, en urna, en cistas funerarias, bajo grandes bloques pircados, dentro de recintos de piedra, etc.), acumulaciones de materiales cerámicos y/o líticos, recintos de piedra aislados o en pequeños grupos en el campo, conjuntos de pocos recintos o importantes aglomeraciones de estructuras formando poblados o aldeas, tanto sobre las terrazas altas de los ríos como en la cima de mesadas o lomadas de mayor (o gran) altura, y extensas construcciones de andenes de cultivo, con estanques, tomas de agua y acequias (Sempé 1999).

Si nos referimos estrictamente a poblados o aldeas que superen los cuatro o cinco recintos, estos siempre han sido localizados a varios metros de altura por sobre el nivel inmediato del terreno, sea este el cauce de un río o el pie de una mesada, loma o cerro. Esta disposición llama la atención considerando que a la vera de los cursos principales -Hualfín, 
Ichanga, Corral Quemado/San Fernando- se extienden amplias terrazas bajas ideales para la instalación humana, con un acceso directo al agua y a campos fácilmente irrigables. Estos espacios hoy día son ocupados por puestos en muchas localidades. Si los poblados más importantes se hubieran emplazado en esas terrazas bajas serían frecuentes los hallazgos de conjuntos más o menos numerosos de viviendas, y este no es el caso. Por el contrario, hasta el momento los mayores poblados conocidos corresponden a sitios emplazados a cierta altura, entre los cuales hemos analizado en diferentes grados los siguientes (Figura 1): (1) Loma de La Toma, (2) Cerro Colorado (La Ciénaga de Abajo), (3) Cerrito Colorado (La Ciénaga de Arriba), (4) Loma de Ichanga (La Ciénaga de Abajo), (5) Loma de Palo Blanco, (6) Loma de los Antiguos (Asampay), (7) Loma de San Fernando, (8) Pueblo Viejo de El Eje, (9) El Molino y (10) Loma de la Escuela Vieja (Puerta de Corral Quemado), 11) Mesada de La Banda y (12) Cerro Pabellón (Corral Quemado), y (13) Loma de Villavil.

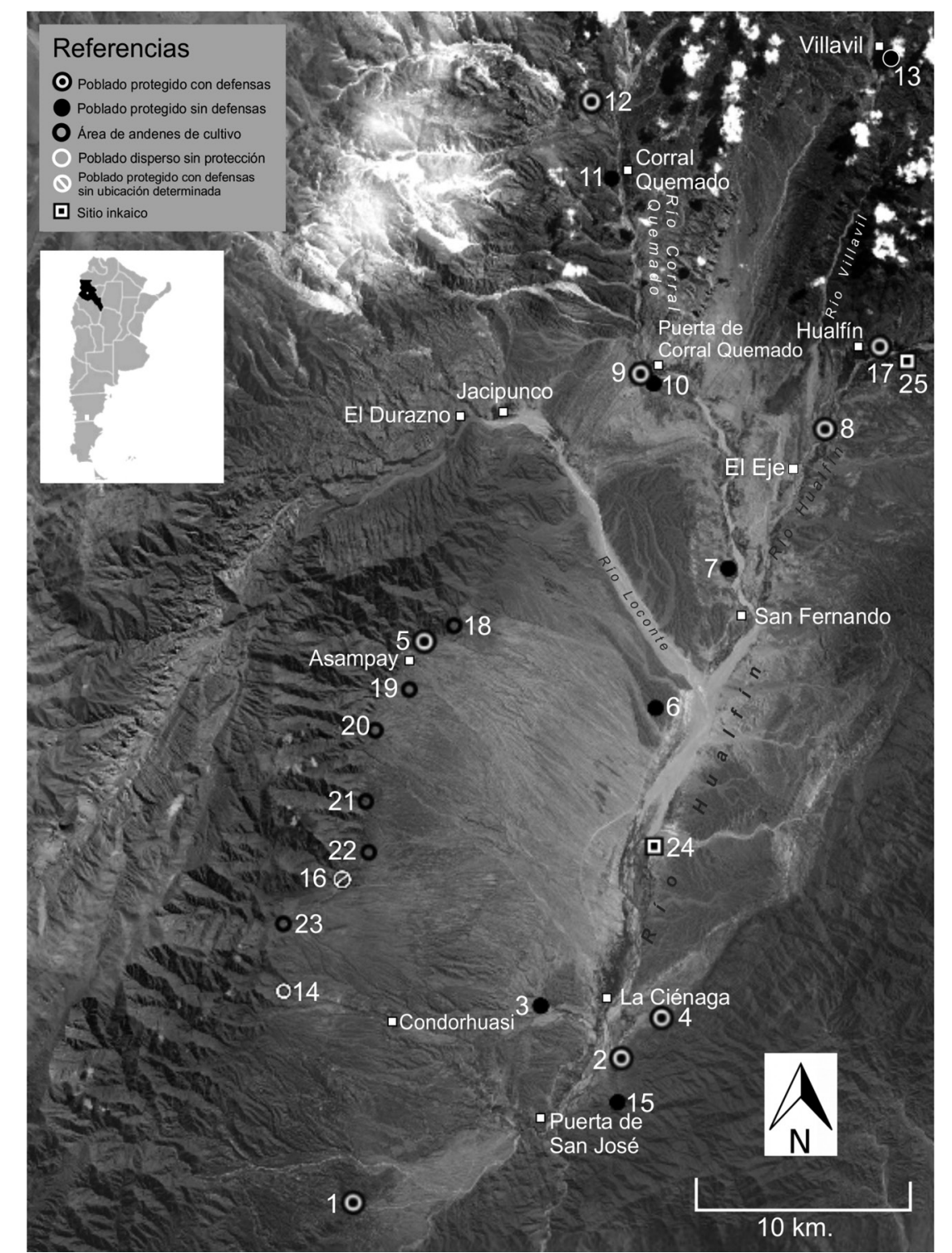

Figura 1. Imagen satelital del Valle de Hualfín con los sitios y localidades referidos en el texto. 
La información disponible en cada caso es diferente, habiendo sido algunos objeto de varias investigaciones, mientras que otros se han incorporado recientemente a los estudios arqueológicos. En algunos de ellos se han llevado a cabo varias excavaciones y planimetrías completas, mientras que en otros únicamente se han realizado prospecciones y relevamientos topográficos parciales, y aún esperan ser excavados sistemáticamente. Aunque para casi la mitad de estos sitios no se han obtenido fechados absolutos, los hallazgos en superficie y las características generales de los asentamientos nos llevan a considerarlos en conjunto, al menos hipotéticamente, como "tardíos". En este sentido, no está de más aclarar que nuestra propuesta es sólo una reconstrucción tentativa, factible de modificar, enmendar, y seguramente ampliar en un futuro.

Como puede advertirse en la Figura 1 se incluyen otros sitios con el fin de ilustrar el marco general en el que se emplazan los poblados protegidos analizados. Por un lado existen varias áreas de andenes de cultivo sobre la ladera occidental del valle (18 a 22). También se conoce un poblado disperso sin protección [Corral de Ramas (14)], cuyo estudio fue realizado por González (1955) en sus primeras intervenciones en el valle, y a partir del cual dicho autor definió la fase I para la cultura Belén. Además, se indica un poblado protegido con defensas [Huasayacu (16)] que aún no ha sido visitado, y si bien es mencionado en la bibliografía (Sempé 1999), no se conoce su exacta localización; y otro protegido sin defensas [La Ramadita (15)], cuya adscripción temporal es aún dudosa. Se señala también la ubicación de las dos instalaciones inkaicas conocidas hasta el momento en el territorio del valle: Quillay (24), definido como un centro metalúrgico (Raffino 1996), y Hualfín Inka (25), un importante tambo cuyos estudios han sido retomados recientemente (Lynch 2010). Estos dos sitios, junto a El Shincal, un centro administrativo ubicado muy próximo al límite geográfico meridional del valle, y Los Colorados, un gran núcleo agrícola que habría sido ocupado desde tiempos pre-tardíos y luego gestionado por el imperio (Giovanetti et al. 2010), son los representantes del dominio regional por parte del Tawantinsuyu. Finalmente, hemos incluido a Pucará de Hualfín "Pozo Verde" (17) (Raffino 2007), un poblado protegido con defensas que al día de hoy se encuentra en estudio, considerando su probable contemporaneidad con las ocupaciones que analizamos.

\section{La dimensión espacial del paisaje tardío}

El territorio que denominamos Valle de Hualfín es de hecho una gran cuenca de unos $70 \mathrm{~km}$ de largo de $\mathrm{N}$ a S, y $20 \mathrm{~km}$ de ancho en sentido E-O, ubicada en el centrooeste catamarqueño. Considerando a grandes rasgos su geomorfología, el valle puede dividirse en dos sectores: el Norte, que comprende unos $30 \mathrm{~km}$. en sentido N-S, extendiéndose aproximadamente desde el Cerro León Muerto hasta la desembocadura del río Loconte en el Hualfín; y el Sur, desde este último punto hasta el Cerro Shincal como extremo meridional. El sector Norte está surcado por los ríos Corral Quemado/ San Fernando, Loconte y Villavil, además del mismo Hualfín, y se caracteriza por un relativo encajonamiento de los cursos de agua y una topografía muy irregular, atravesada por cadenas de lomas de origen sedimentario. En cambio, el sector Sur está dominado por el gran espacio regular que conforma el piedemonte occidental, que desciende casi sin interrupciones desde el cordón del Durazno hasta el río Hualfín (o Belén). Este discurre recostado sobre el lado oriental del valle, al pie de las laderas del cordón del Atajo y la Sierra de Belén. Así, a diferencia del sector Norte, en el sector Sur es visible el valle casi en su totalidad desde lugares relativamente altos, más allá 
de las localizaciones específicas de los sitios. Considerando esta configuración general del marco físico del valle, se presentan las características espaciales de los sitios y luego las condiciones de visibilidad y las relaciones -reales y potenciales- entre ellos. La síntesis de esta información se presenta en las Tablas 1 y 2.

\section{Emplazamiento, configuración espacial y barreras para el acceso}

Todos los sitios analizados presentan un emplazamiento en altura, aunque con muy diferentes dificultades para su acceso, dado que varios se localizan sobre lomadas que rondan los $50 \mathrm{~m}$, mientras que otros se emplazan sobre pequeños cerros de hasta $200 \mathrm{~m}$. Además, la superficie ocupada por el espacio construido en los sitios también varía en gran medida. Desde las 21 has del Cerro Colorado hasta la pequeña lomada de San Fernando, de apenas media hectárea, las construcciones ocupan de maneras muy diferentes el espacio interno.

Cerro Colorado muestra importantes irregularidades en su morfología, incluyendo una ladera que cae a pique, otras con pendientes más suaves aunque irregulares y repletas de obstáculos -grandes paredes de roca, vegetación de distinta clase y tamaño, profundas quebradas, morros de distintas alturas-, y algunos sectores más regulares en la cima a diferentes cotas. Cerrito Colorado también muestra una topografía accidentada, con una pared de jasi en su lado oriental, un cordón del mismo tipo de formación por su flanco sur y laderas algo más suaves hacia el Oeste y Norte, no por eso de fácil acceso. En casos como Loma de La Toma, los pocos recintos existentes se circunscriben a la cima ${ }^{3}$, mientras que dos largas murallas, ubicadas a cierta distancia y a menor altura, amplían el espacio intramuros. Por otra parte, Loma de Palo Blanco presenta un sector de viviendas dispersas sobre una mesada plana y baja, y otro sector más alto, protegido y con menor superficie $(1,1 \mathrm{ha})$ donde se concentran la mayoría de los recintos. Muchos sitios, al emplazarse sobre lomas bien delimitadas, natural o artificialmente, extienden sus construcciones en todo o buena parte del espacio de la cima aprovechable.

En la mayoría de estos poblados existen diferencias de elevación entre los distintos sectores que los componen; los mayores desniveles se observan en el mencionado caso de Cerro Colorado, donde existen agrupamientos de viviendas o "barrios" a diferentes alturas. En Loma de la Escuela Vieja, El Molino, San Fernando, Palo Blanco y Loma de los Antiguos, se distinguen dos niveles de altura para las construcciones. Sin embargo, no hay una modalidad que identifique a uno y otro nivel, y cada caso presenta sus propias características en cuanto al emplazamiento de las estructuras y su disposición interna. En síntesis, no existe un patrón definido para las instalaciones, y los asentamientos se adecuan a la superficie -muy variable- de las lomadas, aprovechándose preferentemente los espacios planos. Por otra parte, la combinación del factor altura con la irregularidad topográfica característica de algunos sitios (principalmente Cerro Colorado, Cerrito Colorado, pero también Cerro Pabellón, Loma de La Toma y Loma de los Antiguos), implican una mayor carga de dificultades para el acceso, a las que se agregan en algunos casos diferentes tipos de barreras, tanto naturales como artificiales.

Los ríos pueden haber funcionado como obstáculos físicos únicamente durante el verano, en época de crecientes, particularmente el Hualfín, el Corral Quemado/ San Fernando y el Villavil, a cuyas orillas se encuentran varios de los sitios estudiados. En algunos casos, como el de Cerro Colorado, las barrancas que separan el río de la base de los sitios debieron funcionar también como una importante barrera natural. Más allá de que la mayoría de los 


\begin{tabular}{|c|c|c|c|c|c|c|c|c|c|c|c|}
\hline \multirow[b]{2}{*}{ Sitio } & \multirow[b]{2}{*}{ Localidad } & \multirow[b]{2}{*}{ 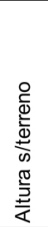 } & \multirow[b]{2}{*}{ 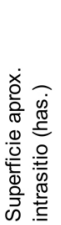 } & \multirow[b]{2}{*}{ 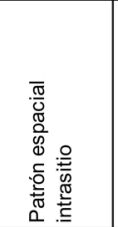 } & \multirow[b]{2}{*}{ 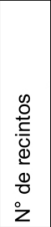 } & \multicolumn{2}{|c|}{$\begin{array}{c}\text { Barreras para } \\
\text { el acceso }\end{array}$} & \multirow{2}{*}{ 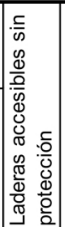 } & \multirow{2}{*}{ 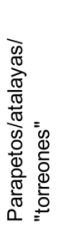 } & \multirow{2}{*}{ 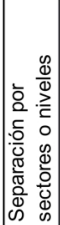 } & \multirow{2}{*}{ 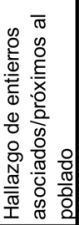 } \\
\hline & & & & & & 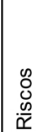 & 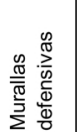 & & & & \\
\hline Loma de La Toma & La Toma & 110 & 1,5 & Aislado & $4^{*}$ & & $x$ & & $\mathrm{X} ?$ & & \\
\hline Cerro Colorado & La Ciénaga de Abajo & 150 & 21 & Aglutinado & 114 & $x$ & $x$ & & $x$ & $x$ & $x$ \\
\hline Loma de Ichanga & La Ciénaga de Abajo & 50 & 8,2 & Aislado & 15 & & & $x$ & & & \\
\hline Cerrito Colorado & La Ciénaga de Arriba & 150 & 7 & Aislado & 20 & $x$ & $X ?$ & & $x$ & $x$ & \\
\hline Loma de los Antiguos & Asampay & 200 & 2,2 & Aglutinado & 44 & & $x$ & & $x$ & $x$ & $x$ \\
\hline Loma de Palo Blanco & Palo Blanco & 60 & 10,3 & Aislado & 50 & & $X ?$ & $x$ & & $x$ & $?$ \\
\hline San Fernando & San Fernando & 50 & 0,55 & Aislado & 20 & & & $x$ & & $x$ & $?$ \\
\hline Pueblo Viejo de El Eje & El Eje & 40 & 1,6 & Aglutinado & 70 & $x$ & $x$ & & & $x$ & $x$ \\
\hline Loma de la Escuela Vieja & Puerta de Corral Quemado & 50 & 4,6 & Aislado & 50 & & & $x$ & & $x$ & \\
\hline El Molino & Puerta de Corral Quemado & 70 & 3,2 & Aglutinado & 116 & & $x$ & & $x$ & $x$ & $x$ \\
\hline Mesada de la Banda & Corral Quemado & 25 & 5,5 & Aislado & 38 & & & $x$ & & & \\
\hline Cerro Pabellón & Corral Quemado & 95 & $\mathrm{~s} / \mathrm{d}$ & Aglutinado & 20 & $x$ & $x$ & & $x$ & & $x$ \\
\hline Loma de Villavil & Villavil & 50 & $s / d$ & Aislado & $\mathrm{s} / \mathrm{d}$ & & $X ?$ & $x$ & & & \\
\hline
\end{tabular}

Tabla 1. Características espaciales de los poblados protegidos analizados

cursos de agua son transitorios y que su incidencia en cuanto al caudal debió ser mínima como obstáculo para su traspaso, excepto en momentos muy determinados, el hecho de que sean verdaderos arenales, parcialmente descubiertos de vegetación, con tonalidades claras que resaltan los contrastes a la vista, convierte a los ríos en espacios muy expuestos si se observan desde determinada altura.

En cuanto a las barreras artificiales, estas se encuentran en la mayoría de los sitios, y están constituidas por murallas y sistemas de muros múltiples. Los sitios en los que mejor representados se encuentran estos rasgos son Loma de La Toma, Cerro Colorado, Loma de los Antiguos, Pueblo Viejo de El Eje y El Molino (Figura 2). Por otro lado, no debe descartarse la posible inclusión en todos los sitios de barreras construidas con material perecedero como adobe, madera o vegetación espinosa, hoy día empleadas muy eficazmente por los pobladores actuales para delimitar sus campos y protegerlos de los animales.

Sólo en Loma de los Antiguos las murallas delimitan por completo el espacio intrasitio. En los restantes poblados en los que existen murallas, a veces de varias decenas a cientos de metros de largo, estas se encuentran restringidas a las laderas más vulnerables. Esto último demuestra que su función debió estar ligada a la defensa. Un ejemplo son las dos líneas de muralla de Loma de La Toma, que en algunos sectores se conservan en muy buen estado, mientras que en otros están totalmente derrumbadas por la acción de las cárcavas que erosionan constantemente el terreno (Figura 3). La línea superior es más corta (89 m), y recorre todo el sector noroccidental de la cima. En su extremo oeste se une a la muralla inferior. Esta última tiene $270 \mathrm{~m}$ de longitud, y se extiende desde un sector aterrazado con estructuras ubicado próximo al extremo norte, surcando toda la ladera noroeste de la lomada, hasta alcanzar la cima en el punto más occidental del sitio. Cabe señalar que la ladera noroeste, totalmente amurallada, es la que presenta menor pendiente $(17 \%)$, mientras que los flancos noreste y sur, ambos sin murallas, llegan al $40 \%$ y 33\% respectivamente. Las murallas de Cerro Colorado y Pueblo Viejo de El Eje también atraviesan las laderas más accesibles, como ilustramos en la Figura 2. 

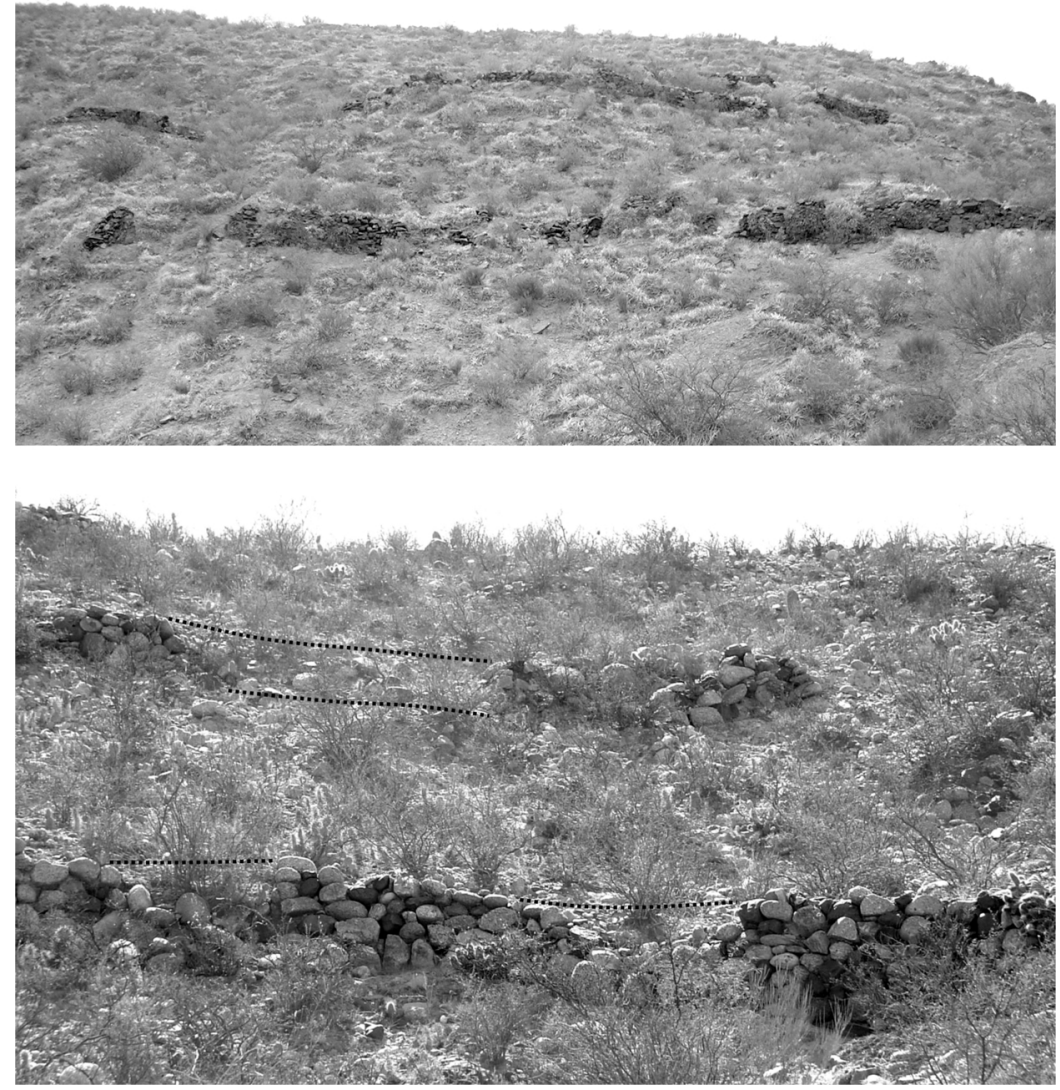

Figura 2. Ejemplos de murallas defensivas. Arriba: ladera occidental del Cerro Colorado (La Ciénaga de Abajo). Abajo: ladera occidental del Pueblo Viejo de El Eje; las líneas punteadas indican los sectores derrumbados

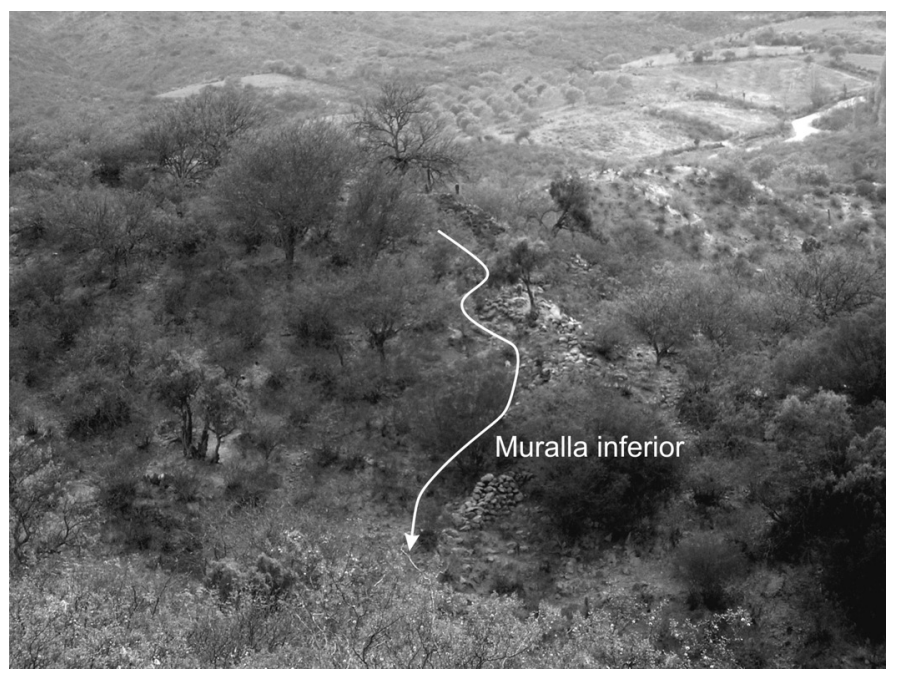

Figura 3. Muralla defensiva ubicada en la ladera noroeste de Loma de La Toma. Nótese el corte de una cárcava en el sector del extremo de la flecha. 
Más allá de la protección explícita de muchos de estos poblados, representada por riscos, murallas y parapetos, y de cierto nivel de inaccesibilidad que la mayoría de ellos muestra en cuanto a su emplazamiento, algunos presentan laderas bastante accesibles, sin protección alguna. Son los casos de Loma de Ichanga, el sector inferior de Loma de Palo Blanco y de Loma de la Escuela Vieja, San Fernando y Mesada de La Banda. Justamente las sendas de acceso a estas lomas actualmente recorren dichas laderas. Si se interpretaran estos asentamientos en términos defensivos clásicos, la ausencia de los rasgos "típicos" de los sitios fortificados llevaría a descartar una necesidad de protección por parte de sus ocupantes. Sin embargo, creemos que la evaluación del carácter protegido de una ocupación no puede ni debe efectuarse en términos absolutos, sino considerando las características de los grupos involucrados en un eventual conflicto, el contexto socio-político general en el que se inserta un sitio, y las situaciones particulares que pudieron intervenir en el vínculo entre dichos grupos. Por otra parte, ya mencionamos la posibilidad de la existencia de barreras perecederas que pudieron ser muy efectivas en situaciones de violencia entre grupos poco numerosos que portaran armas como las que debieron emplearse en tiempos prehispánicos (Nielsen 2007).

Retomando el análisis del conjunto general de los sitios, la orientación de los accesos en ciertos recintos sugiere la existencia de verdaderos puestos de observación o divisaderos. En algunos sitios hay parapetos a distintas alturas, construidos con pircas dobles, a veces antecedidos por una muralla, "colgados" de barrancos o sobre la cima de pequeñas lomadas más o menos aisladas (Figura 4).

En cuanto a la posibilidad de identificar entradas diseñadas defensivamente, sólo en los sitios más complejos como Loma de los Antiguos, Pueblo Viejo de El Eje, El Molino y Cerro Colorado se observan algunas murallas con aperturas a modo de accesos, que pudieron

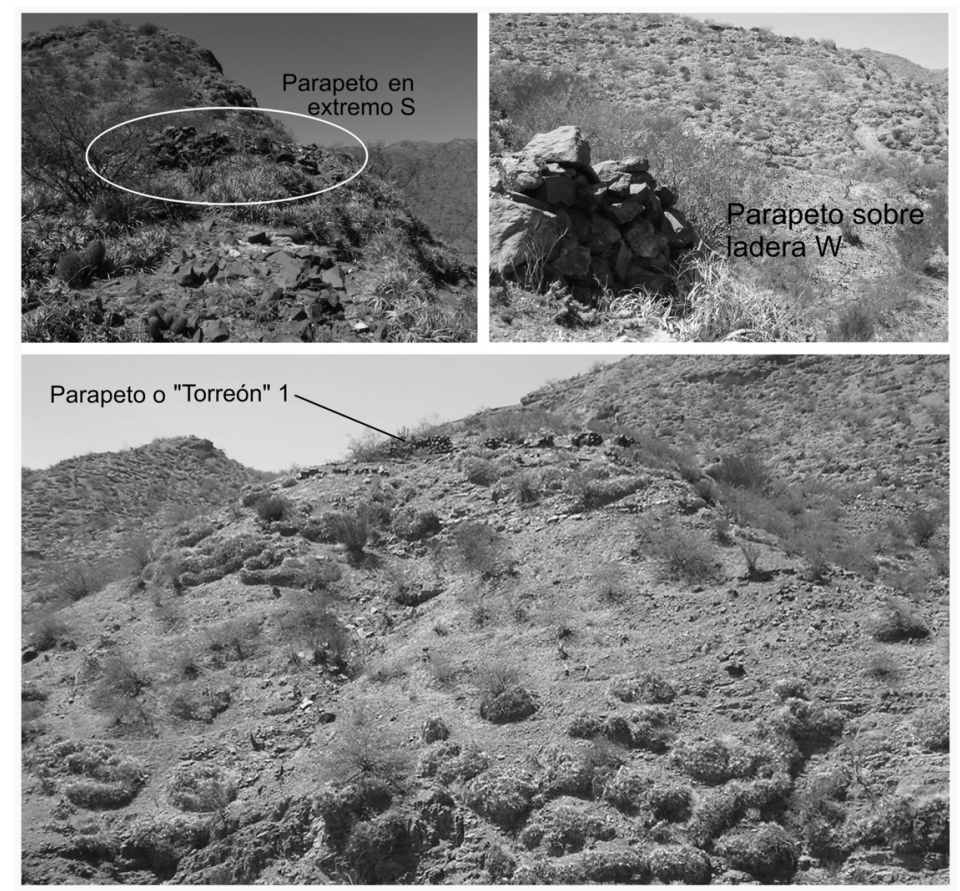

Figura 4. Parapetos o "torreones" en el Cerro Colorado (La Ciénaga de Abajo). 
utilizarse sobre todo para una rápida circulación en el ascenso y descenso, pero también en situaciones de defensa, como "embudos" que irremediablemente debían trasponer los atacantes si su intención era flanquear esas barreras, detrás de las cuales los defensores podían parapetarse para rechazar los ataques. Por otro lado, los conjuntos de recintos intercomunicados de estos sitios más complejos generan espacios restringidos al acceso, que sólo quienes tuvieran un conocimiento cabal del sentido de circulación podían recorrer con facilidad.

Con respecto a la configuración espacial intrasitio, los poblados protegidos pueden clasificarse en términos generales en dos tipos: por un lado, los sitios con recintos casi exclusivamente aislados, a lo sumo formando conjuntos de dos estructuras, y por el otro, sitios con agrupaciones de tres o más recintos, comunicados por pasillos y/o compartiendo paredes. Los sitios de patrón aislado son Loma de La Toma, Cerrito Colorado, Loma de Ichanga, Loma de Palo Blanco, Loma de San Fernando, Loma de la Escuela Vieja, Mesada de La Banda y Loma de Villavil. Si bien todos estos poblados presentan esta característica general, difieren en gran medida en cuanto a la concentración de las estructuras, incluso dentro de un mismo poblado. En Loma de la Escuela Vieja, por ejemplo, la distribución de los recintos es bastante regular y concentrada (Figura 5); en cambio, en Loma de Palo Blanco existen diferencias internas: el sector del "pukara" presenta una alta concentración de recintos, mientras que en la mesada inferior las estructuras están mucho más dispersas. Cerrito Colorado es un caso particular, ya que sus recintos no se emplazan en uno o dos espacios más o menos regulares, sino a muy diferentes cotas, en pequeños sectores planos, bastante aislados entre sí.

Los poblados de patrón aglutinado serían Cerro Colorado, Loma de los Antiguos, Pueblo Viejo de El Eje, El Molino y Cerro Pabellón. Ya se mencionó la complejidad interna de Cerro Colorado, con sus "barrios" emplazados a distintas cotas, conformados por varios conjuntos de recintos asociados. En Loma de los Antiguos se observa un núcleo central de numerosos recintos asociados, dispuestos alrededor de un gran patio, y otros conjuntos más dispersos, ubicados en los márgenes del sitio, más próximos a las murallas de circunvalación (Figura 6). El poblado con mayor concentración de estructuras conocido hasta el momento es El Molino, con un patrón excepcional para el valle cuya apariencia

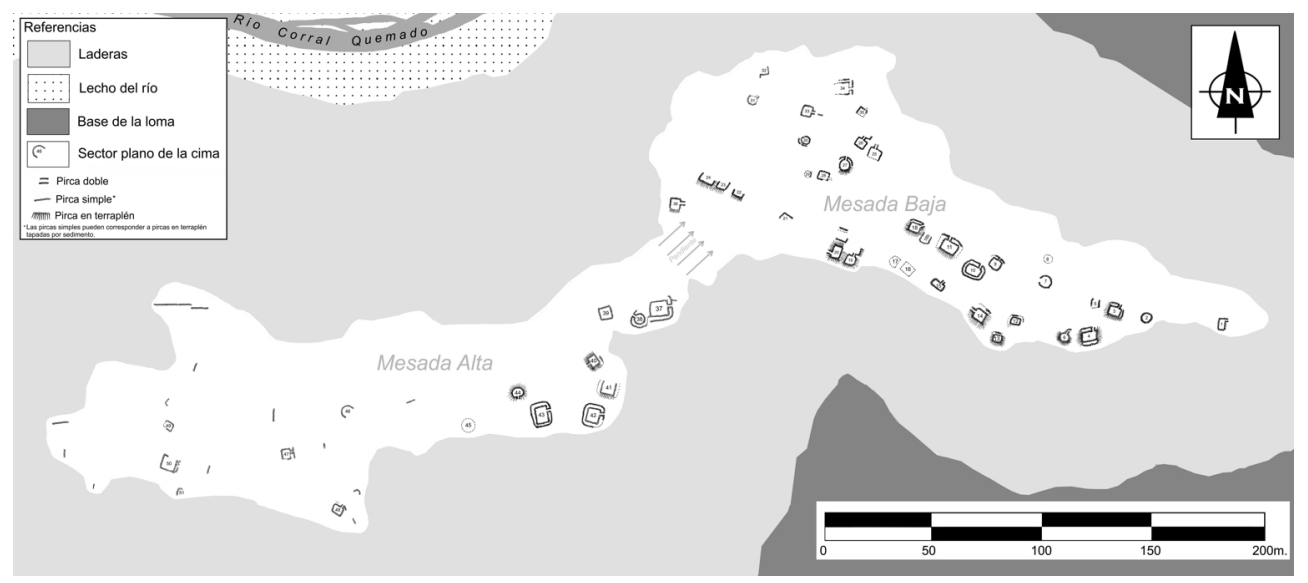

Figura 5. Plano de Loma de la Escuela Vieja (Puerta de Corral Quemado). 


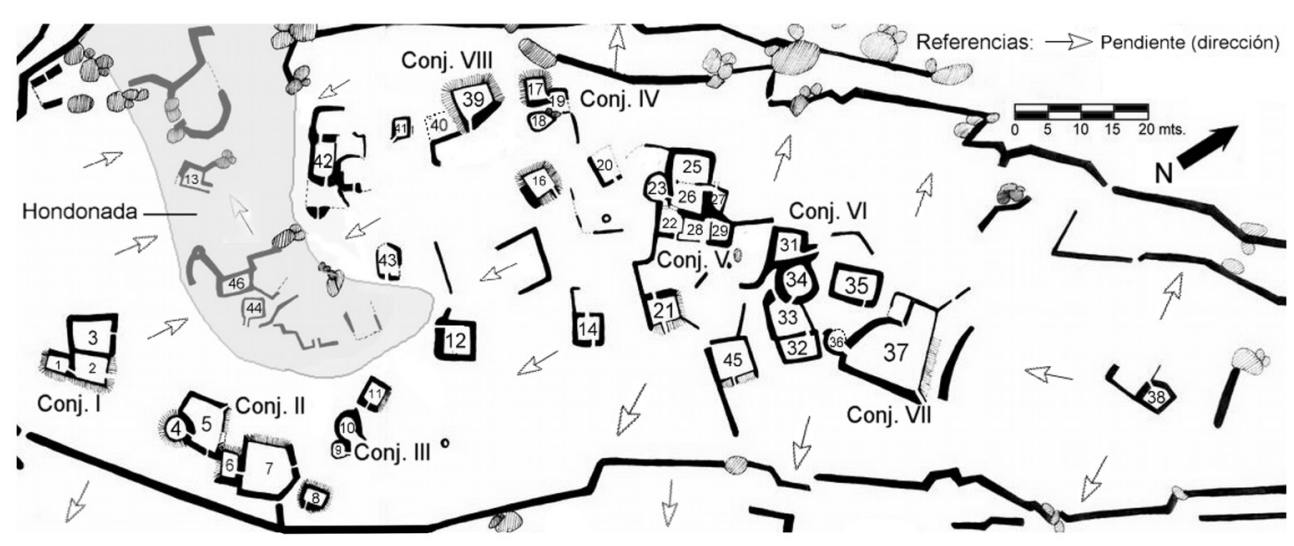

Figura 6. Detalle de los conjuntos de estructuras intrasitio de Loma de los Antiguos de Asampay.

recuerda más a algunos sitios de los valles del Cajón o Yocavil que a los sitios locales, más dispersos y generalmente menos densos (Nastri 1997-98; Tarragó 1987; Raffino 2007; Rivolta y Salazar 2007; Bugliani 2012, entre muchos otros).

\section{Campo visual, visibilidad e intervisibilidad}

Siguiendo con la dimensión espacial de los poblados protegidos tardíos, un aspecto fundamental para el análisis de la percepción espacial es el del campo visual que es posible de obtener desde la cima de estos sitios. En primer lugar, la visualización del entorno inmediato permitía un control directo de los accesos a los lugares más cercanos, donde la proximidad del río le daba al entorno un carácter abierto. En este sentido, los grupos dispersos entre los campos de cultivo cercanos a las terrazas de los ríos podrían haber sido rápidamente alertados acerca de algún peligro inminente. Por otro lado, la intervisibilidad de los sitios pudo ser una variable importante en tiempos de conflictos, fueran estos internos o producidos por agresiones foráneas, proporcionando apoyos para defensas mutuas a través de señales visuales (Arkush 2009).

Más allá del campo visual "objetivo" que se logra desde cada sitio, existe una variedad de condiciones de visibilidad que dependen del comportamiento de la atmósfera -y por ende, de las épocas del año y de los momentos del día-, con lo cual la intervisibilidad entre los sitios varía considerablemente de acuerdo a las distancias. Se observa mucha diferencia en cuanto a la visibilidad en días (o momentos del día) diáfanos frente a los momentos en los que abunda la niebla, sobre todo en la falda occidental, que impide ver toda la cadena de cerros y las lomas al pie; en ocasiones la niebla llega incluso a limitar la vista a sólo unas decenas de metros. Son comunes también las tormentas de tierra, que pueden nublar la vista por varios días, reduciendo la visibilidad a cientos de metros o pocos kilómetros. Todas estas condiciones debieron ser consideradas por los actores al momento de atacar y defender un poblado. Y, si abogamos por la hipótesis de un vínculo comunicacional entre los sitios, debieron también influir en la elección de los lugares para la construcción de los poblados, en función de quiénes serían los interlocutores en los intercambios de información visual (parientes, grupos aliados, etc.). 
Teniendo en cuenta estos probables condicionamientos, se realizó un análisis de intervisibilidad entre los sitios protegidos (Tabla 2 y Figura 7). Para llevarlo a cabo se proyectaron líneas de unión visual entre los sitios sobre una imagen satelital tratada con GIS, contrastándose las relaciones de visibilidad en el terreno para la mayoría de los casos. Habiéndose detectado en un principio que las líneas entre algunos sitios estaban interrumpidas por diferentes elevaciones, se buscaron alternativas de intervisibilidad en relación a puntos del terreno próximos a los poblados en los cuales existen estructuras arqueológicas. Por otra parte, cuando no se tuvo registro de otras estructuras aledañas, se generaron líneas de visión indirectas sobre puntos probables de conexión. Estas dos variantes indirectas únicamente se consideraron para distancias menores a $10 \mathrm{~km}$, teniendo en cuenta que distancias mayores implicarían, además de cierta incertidumbre en cuanto a la comunicación (en función de la variación en las condiciones de visibilidad), la inseguridad ante la falta de una comunicación directa con el núcleo de mayor concentración de gente en cada localidad.

De esta manera, se clasificaron las relaciones en función de cinco categorías, según fueran directas o indirectas, y de acuerdo a las distancias: 1) indirectas menores a $10 \mathrm{~km}$ con intervisibilidad desde estructuras próximas al poblado; 2) indirectas menores a $10 \mathrm{~km}$ a través de un potencial sitio intermedio; 3) directas menores a $10 \mathrm{~km}, 4$ ) directas mayores a $10 \mathrm{~km}$ y menores $20 \mathrm{~km}$, y 5) directas mayores a $20 \mathrm{~km}$. Debe aclararse que las relaciones de intervisibilidad señaladas no implican que fueran las únicas líneas para una potencial comunicación visual. Seguramente existieron más poblados que hasta el momento no han sido detectados y que agregarán más relaciones al paisaje. Además, como se mencionó para los casos de relaciones indirectas, es muy probable la existencia de puestos intermedios que permitieran una comunicación más fluida. Esos puntos de contacto pueden haber sido provisorios, quizás utilizados con más frecuencia en momentos de mayor conflictividad, en los que se haría necesaria una vigilancia más estricta. Sin embargo, la relevancia de la intervisibilidad directa entre los sitios de mayor densidad poblacional es evidente, considerando que una mayor proporción de la población podía haber sido prevenida inmediatamente ante un eventual peligro.

Como puede advertirse tanto en la imagen satelital de la Figura 7 como en la Tabla 2, todos los poblados protegidos tardíos correspondientes al Sector Sur que hemos incluido en el análisis tienen relaciones directas de intervisibilidad. Por tanto, en este caso las diferencias en cuanto a las líneas de visión se deben únicamente a las distancias. Si se consideran las distancias menores a $10 \mathrm{~km}$, únicamente se vinculan los tres sitios de La Ciénaga (Loma de Ichanga, Cerro Colorado y Cerrito Colorado). Las distancias mayores a $10 \mathrm{~km}$ y menores a $20 \mathrm{~km}$ permiten conectar directamente, por un lado a Loma de La Toma con los tres sitios de La Ciénaga mencionados, por otro a Loma de los Antiguos con Loma de Palo Blanco y Loma de Ichanga, y finalmente a los tres sitios de La Ciénaga con Loma de Palo Blanco. En síntesis, con condiciones óptimas de visibilidad el Sector Sur es un espacio que permite una intervisibilidad absoluta entre estos sitios; además, existiendo ciertos condicionamientos climáticos o atmosféricos, las relaciones entre sitios más o menos próximos, separados por menos de $20 \mathrm{~km}$, también son directas en gran medida.

Muy diferente es la situación en el Sector Norte. En principio, la intervisibilidad con los sitios protegidos del Sector Sur no es directa en ningún caso. La proximidad de Loma de Palo Blanco con Loma de San Fernando nos llevó a evaluar posibles vínculos visuales indirectos, por ejemplo, con sitios intermedios que se emplazaran en la banda Este del río Hualfín a la altura de la desembocadura del río Corral Quemado/San Fernando. Aún no hemos hallado 


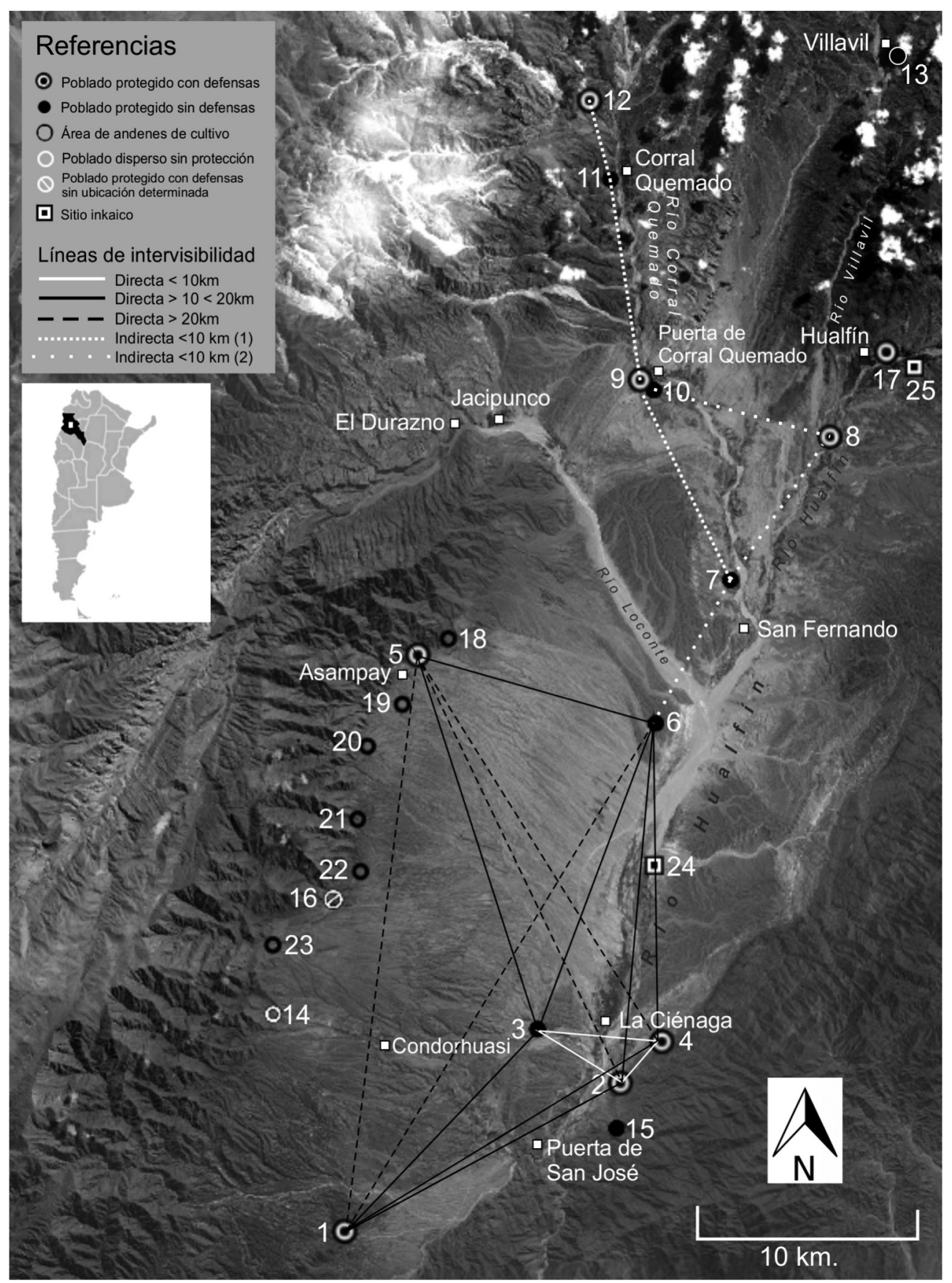

Figura 7. Imagen satelital del Valle de Hualfín con la representación de los diferentes tipos de líneas de visibilidad entre los sitios protegidos analizados. 


\begin{tabular}{|c|c|c|c|c|c|c|c|c|c|c|c|c|c|c|}
\hline Sitio & Localidad & 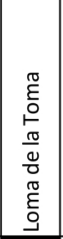 & 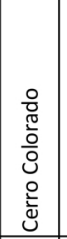 & 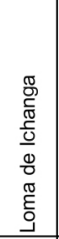 & 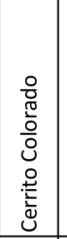 & 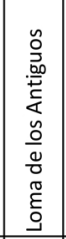 & 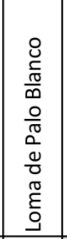 & 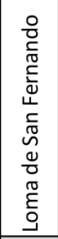 & 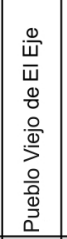 & 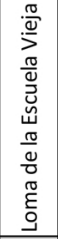 & 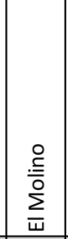 & 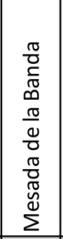 & $\begin{array}{l}\text { 흐 } \\
\overline{0} \\
0 \\
0 \\
0 \\
0 \\
0 \\
0 \\
0\end{array}$ & 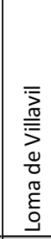 \\
\hline Loma de la Toma & La Toma & & $d>10$ & $d>10$ & $d>10$ & $d>20$ & $d>20$ & & & & & & & \\
\hline Cerro Colorado & La Ciénaga de Abajo & $d>10$ & & $\mathrm{D}$ & $\mathrm{D}$ & $d>20$ & $d>20$ & & & & & & & \\
\hline Loma de Ichanga & La Ciénaga de Abajo & $d>10$ & $\mathrm{D}$ & & $D$ & $d>10$ & $d>10$ & & & & & & & \\
\hline Cerrito Colorado & La Ciénaga de Arriba & $d>10$ & D & D & & $d>20$ & $d>10$ & & & & & & & \\
\hline Loma de los Antiguos & Asampay & $d>20$ & $d>10$ & $d>20$ & $d>20$ & & $d>10$ & & & & & & & \\
\hline Loma de Palo Blanco & Palo Blanco & $d>20$ & $d>10$ & $d>10$ & $d>10$ & $d>10$ & & ind(2) & & & & & & \\
\hline Loma de San Fernando & San Fernando & & & & & & ind(2) & & ind(2) & ind(1) & ind(1) & & & \\
\hline Pueblo Viejo de El Eje & EI Eje & & & & & & & ind(2) & & ind(2) & $\operatorname{ind}(2)$ & & & \\
\hline Loma de la Escuela Vieja & Puerta de Corral Quemado & & & & & & & ind(2) & ind(2) & & $\mathrm{D}$ & & & \\
\hline El Molino & Puerta de Corral Quemado & & & & & & & ind(2) & ind(2) & $\mathrm{D}$ & & ind(1) & & \\
\hline Mesada de la Banda & Corral Quemado & & & & & & & & & & $\operatorname{ind}(1)$ & & ind(1) & \\
\hline Cerro Pabellón & Corral Quemado & & & & & & & & & & & $\operatorname{ind}(1)$ & & \\
\hline Loma de Villavil & Villavil & & & & & & & & & & & & & \\
\hline \multicolumn{15}{|l|}{ Referencias } \\
\hline \multicolumn{15}{|c|}{ D: visibilidad directa, con distancia menor a $10 \mathrm{~km}$} \\
\hline \multicolumn{15}{|c|}{$\mathrm{d}>10$ : visibilidad directa con distancia mayor a $10 \mathrm{~km}$ y menor a $20 \mathrm{~km}$} \\
\hline \multicolumn{15}{|c|}{$\mathrm{d}>20:$ visibilidad directa con distancia mayor a $20 \mathrm{~km}$} \\
\hline \multicolumn{15}{|c|}{$\begin{array}{l}\text { ind(1): visibilidad indirecta con distancia menor a } 10 \mathrm{~km} \text {; se conocen estructuras arqueológicas próximas fuera del poblado, desde las } \\
\text { cuales existe intervisibilidad }\end{array}$} \\
\hline \multicolumn{15}{|c|}{$\begin{array}{l}\text { ind(2): visibilidad indirecta menor a } 10 \mathrm{~km} \text {; no existe intervisibilidad, aunque la proximidad permitiría una comunicación indirecta por un } \\
\text { sitio intermedio. }\end{array}$} \\
\hline
\end{tabular}

Tabla 2. Intervisibilidad para los sitios protegidos tardíos del Valle de Hualfín.

tales sitios, y tampoco lo hicieron los antiguos expedicionarios que trabajaron en la zona (Weiser y Wolters 1923-1926). También hubo dificultades para lograr relaciones de visibilidad entre los propios sitios del Sector Norte (más allá de El Molino y Loma de la Escuela Vieja, separados por apenas unos $600 \mathrm{~m}$ ). Sin embargo, la existencia de estructuras arqueológicas emplazadas a buena altura, ubicadas al Sur de Loma de la Escuela Vieja permite conectar visualmente Puerta de Corral Quemado con Loma de San Fernando; y si se considera un sector de estructuras ubicado en una mesada alta contigua al poblado Mesada de la Banda (Corral Quemado) como parte del sitio, vemos que se logra intervisibilidad con El Molino y con Cerro Pabellón. Por otro lado, tampoco hemos logrado vincular directamente Loma de San Fernando y los sitios de Puerta de Corral Quemado con Pueblo Viejo de El Eje, a pesar de ubicarse bastante próximos entre sí. Podríamos suponer que existieron conexiones visuales indirectas entre estos sitios, sobre todo si se tienen en cuenta los pocos obstáculos que impiden una visión directa. Finalmente, el poblado más alejado del conjunto analizado, Loma de Villavil, no presenta intervisibilidad con ningún sitio conocido hasta el momento. Harán falta nuevas prospecciones en la zona del extremo Norte del valle (hasta el momento, la menos estudiada) para comprender cabalmente la relación entre este sitio y el resto de los asentamientos de la región. Por lo pronto, podría pensarse en que probablemente esta zona tuviera un vínculo más estrecho con el área del Valle del Bolsón, al norte.

Más allá de la fragmentación visual que se observa entre los sitios protegidos del Sector Norte, los aportes que puedan brindar en un futuro las investigaciones en el sitio Pozo Verde de Hualfín quizás cambien el panorama, considerando que dicho sitio se encuentra en un área estratégica del valle, como es el acceso al mismo desde el Campo del Arenal. 


\section{Reconstruyendo relaciones en un espacio controlado y defendido}

Como resultado de los análisis realizados hemos comprobado, en primer lugar, que existe una importante variabilidad en cuanto al área ocupada por las construcciones, la topografía sobre la que se emplazan y la configuración, distribución interna y número de las estructuras de habitación. También se observa gran diversidad con respecto a las dificultades de acceso a los poblados analizados, las barreras naturales o artificiales y la presencia/ausencia de estructuras claramente defensivas, existiendo sitios que pueden considerarse verdaderas fortalezas y otros muy desguarnecidos. Sin embargo, sostenemos que al enfocarnos en los poblados sin fortificación debe considerarse, además del resguardo natural del emplazamiento en altura, la protección que otorga el campo visual obtenido desde los sitios, que permite controlar tanto el entorno más próximo al sitio como los espacios más distantes y los principales corredores de acceso a cada lugar, además de garantizar en la mayoría de los casos una comunicación fluida con otras poblaciones y facilitar el conocimiento acerca de los movimientos ocurridos en y entre ellas. El emplazamiento sobre esas lomadas ubicadas a la vera de cursos de agua, bien pudo persuadir a potenciales atacantes sobre la inconveniencia de acceder al río y a los campos al pie, o de aventurarse por las laderas del poblado. En este punto, la percepción del límite físico conformado por el perímetro de las lomadas -y no únicamente las murallas defensivas- también debió ser relevante, ya que pudo evocar un límite simbólico en quienes lo percibieran, reforzando la idea de la unidad del conjunto de cada poblado. Estas ideas serían insostenibles si se las interpretara desde los puntos de vista clásicos de la guerra, pero cobran sentido al evaluarse desde una perspectiva local y contextualizada, considerando tanto la duración como la escala particular de los conflictos que pudieron presentarse en épocas pre-inkaicas, desde el tipo y grado de daños que podían provocar las armas disponibles, hasta el número de personas que conformarían los posibles grupos hostiles. Si bien hasta el momento existen escasas evidencias de conflictos armados o de violencia física directa en el valle (más allá de los poblados protegidos), en toda el Área Centro Sur Andina se han registrado guerras constantes durante el período considerado (Nielsen 2007). Este contexto general lleva a preguntarnos con qué frecuencia se desarrollaban conflictos violentos entre las poblaciones locales y entre estas y sus vecinos, y cómo se habrían adecuado políticamente a estas situaciones; si realmente conformaron "sociedades guerreras" o si simplemente eran "sociedades con guerreros" (González García 2009), qué poblados protegidos funcionaron como refugios durante momentos particularmente violentos y cuáles pudieron ser ocupados ininterrumpidamente.

Otro aspecto interesante a tratar (y profundizar) en relación a la protección de estos poblados es el hallazgo de entierros humanos dentro y/o en los alrededores de algunos de estos poblados (Tabla 1), incluso dentro de las propias murallas defensivas (Wynveldt 2009). Salvando las distancias (geográficas y de grado) Nielsen (2002) sugiere que las chullpas pudieron tener una función de protección de los antepasados para con los vivos en los pukaras del Norte de Lípez (Bolivia), además de haber actuado probablemente como legitimadoras de los derechos de ocupación del territorio por parte de determinados linajes. Creemos que no deberían descartarse este tipo de "indicadores" que no figuran en las listas de rasgos defensivos pero que indudablemente debieron tener su importancia en las decisiones y acciones de los individuos, en nuestro caso en su rol de atacantes y defensores. La ritualización entonces, pudo dar carácter sagrado a los sitios, materializando, a partir del culto a los antepasados, los derechos de posesión de la tierra. 
Finalmente, en cuanto al análisis de la intervisibilidad hemos diferenciado el Sector Sur, en el que todos los sitios son visibles entre sí, más allá de las diferentes distancias que los separan, y el Sector Norte, donde para la mayoría de estos poblados harían falta puntos intermedios para lograr al menos relaciones indirectas de intervisibilidad. Estas diferencias nos llevan a considerar algunas interpretaciones que pueden apoyarse en el análisis de las restantes dimensiones del paisaje que proponemos: la dimensión temporal y la dimensión de los objetos materiales.

\section{Hacia una reconstrucción del paisaje tardío del Valle de Hualfín}

Enfocándonos en determinados indicadores de la dimensión espacial del paisaje, hemos analizado una serie de poblados protegidos tardíos del Valle de Hualfín. A pesar de las diferencias halladas en relación a muchos de esos indicadores, existen también importantes evidencias que sugieren un vínculo estrecho entre los grupos que habitaron estos sitios. En cuanto a lo espacial, ya hemos mencionado el emplazamiento en altura, más allá de las diferencias de grado, como una modalidad compartida de asentamiento.

Si analizamos brevemente un aspecto de la dimensión temporal como es la cronología absoluta, vemos también diferencias y similitudes en cuanto a la ocupación de estos sitios. En la Tabla 3 se presentan las edades radiocarbónicas que consideramos aceptables para los sitios analizados en función de diferentes argumentos sostenidos en otros trabajos (Wynveldt 2009; Wynveldt e Iucci 2013). A simple vista puede notarse cierta continuidad en toda la serie. Sin embargo, efectuando un test de significación con el programa Calib Rev 6.1.0 pudimos constatar que las muestras son significativamente diferentes para un $95 \%$ de probabilidad. El test cambia si se tienen en cuenta sólo las diez edades más antiguas, incluyéndose fechados para todos los sitios excepto Loma de los Antiguos de Asampay. En este sentido, más allá de las diferentes edades que se hayan obtenido para un mismo sitio, puede interpretarse que Pueblo Viejo de El Eje, El Molino, Cerrito Colorado, Cerro Colorado, Loma de la Escuela Vieja y Loma de Ichanga tuvieron ocupaciones relativamente contemporáneas, muy probablemente coincidentes a lo largo del siglo XV, y quizás reflejen en algunos casos las últimas ocupaciones preinkaicas, y en otros el abandono de determinados sitios ya durante época inka. Por otra parte, puede sugerirse que el sitio Loma de los

\begin{tabular}{|c|c|c|c|c|c|c|c|c|}
\hline \multirow{3}{*}{$\begin{array}{c}\text { Sitio } \\
\text { Pueblo Viejo de El Eje, Recinto } 53\end{array}$} & \multirow{3}{*}{$\begin{array}{l}\text { Código } \\
\text { AA94601 } \\
\end{array}$} & \multirow{3}{*}{$\begin{array}{l}\text { Muestra } \\
\text { Lama sp. }\end{array}$} & \multirow{3}{*}{\begin{tabular}{|c|}
$\begin{array}{c}\text { Edad C-14 } \\
\text { AP }\end{array}$ \\
$602 \pm 42$ \\
\end{tabular}} & \multicolumn{5}{|c|}{ Calibración AD (Curva SHcal04) } \\
\hline & & & & \multicolumn{3}{|c|}{1 Sigma } & \multicolumn{2}{|c|}{2 Sigma } \\
\hline & & & & $1323-1345(0,34)$ & $1389-1421(0,66)$ & & $1307-1361(0,38)$ & $1378-1441(0,62)$ \\
\hline El Molino, Recinto 110 & AA88363 & Hueso humano & $585 \pm 44$ & $1328-1336(0,1)$ & $1391-1433(0,9)$ & & $1315-1357(0,25)$ & $1381-1448(0,75)$ \\
\hline Cerrito Colorado; Recinto 3 & U-154 & Algarrobo y jarilla & $580 \pm 80$ & $1318-1352(0,3)$ & $1384-1447(0,7)$ & & 1283-1497 $(1,0)$ & \\
\hline Cerro Colorado, Recinto 36 & AA85880 & Hueso humano & $539 \pm 43$ & $1409-1443(1,0)$ & & & $1327-1340(0,02)$ & $1390-1460(0,98)$ \\
\hline Loma de la Escuela Vieja (Rec. 6) & AA88362 & Maiz carbonizado & $521 \pm 36$ & $1419-1447(1,0)$ & & & $1401-1458(1,0)$ & \\
\hline Pueblo Viejo de El Eje, Recinto 72 & Lu-371 & Carbón vegetal & $520 \pm 50$ & $1410-1452(1,0)$ & & & $1326-1340(0,02)$ & $1390-1499(0,97)$ \\
\hline Cerro Colorado, Recinto 2 & AA94600 & Marlo de maíz & $493 \pm 34$ & $1428-1456(1,0)$ & & & $1408-1487(1,0)$ & \\
\hline Cerrito Colorado, Recinto 3 & LP-1810 & Carbón vegetal & $420 \pm 70$ & $1448-1512(0,52)$ & 1548-1562 (0,09) & $1570-1622(0,39)$ & $1426-1643(1,0)$ & \\
\hline Loma de Ichanga, Recinto 6 & LP-1832 & Marlo de maíz & $420 \pm 50$ & $1449-1510(0,62)$ & $1577-1621(0,37)$ & & $1443-1628(1,0)$ & \\
\hline Cerrito Colorado, Recinto 8 & L-476C & Carbón vegetal & $400 \pm 100$ & $1454-1626(1,0)$ & & & $1395-1689(0,93)$ & $1728-1805(0,07)$ \\
\hline Loma de Ichanga, Recinto 9 & LP-2667 & Camelidae & $360 \pm 50$ & $1500-1597(0,83)$ & $1611-1632(0,17)$ & & $1459-1646(1,0)$ & \\
\hline Loma de los Antiguos, Recinto 3 & LP-1039 & Carbón vegetal & $350 \pm 50$ & $1502-1593(0,79)$ & $1614-1637(0,21)$ & & $1459-1652(1,0)$ & \\
\hline Loma de los Antiguos, Recinto 9 & LP-937 & Carbón vegetal & $330 \pm 50$ & $1505-1588(0,73)$ & $1617-1647(0,27)$ & & $1459-1670(0,98)$ & $1750-1795(0,02)$ \\
\hline Loma de los Antiguos, Recinto 31 & LP-1644 & Hueso humano & $320 \pm 50$ & $1506-1588(0,69)$ & $1617-1651(0,31)$ & & $1464-1672(0,94)$ & $1744-1796(0,06)$ \\
\hline Cerro Colorado, Recinto 35 & LP-2760 & Maíz carbonizado & $290 \pm 60$ & $1509-1580(0,38)$ & $1620-1673(0,38)$ & $\mid 1743-1772(0,13)$ & $1462-1699(0,73)$ & 1722-1809 $(0,25$ \\
\hline
\end{tabular}

Tabla 3. Edades radiocarbónicas calibradas para los sitios protegidos analizados. En negrita figuran las mayores probabilidades en los rangos para uno y dos sigma. 
Antiguos pudo ser utilizado también en tiempos inkaicos e incluso hispano-indígenas, por lo cual los restos datados podrían corresponder a las últimas ocupaciones, borrándose los rastros de momentos anteriores.

Si bien aún es limitada la lista de edades radiocarbónicas, la tendencia indica la existencia de un lazo temporal entre los poblados protegidos analizados. Es decir, además de los vínculos en cuanto a la dimensión espacial, relativos al emplazamiento, variados rasgos de la arquitectura y la intervisibilidad entre la mayoría de estos sitios, si tenemos en cuenta la dimensión temporal podemos afianzar la idea de una coexistencia entre los grupos que los habitaron.

Otro paso más en la tarea de la reconstrucción del paisaje es vincular nuestro análisis de la dimensión espacial con algunos aspectos de la dimensión de los objetos materiales. Esta última apunta a reconstituir las asociaciones entre objetos y personas, considerando su ubicación en el espacio y su incidencia en la conformación de las relaciones sociales. En un primer acercamiento a la distribución a nivel regional de los objetos materiales, sabemos que existen dos tipos de manufacturas que se encuentran en todos los sitios analizados: la cerámica, en sus variantes fina (representada por varios estilos) y ordinaria; y los artefactos de obsidiana, una materia prima procedente de la puna, utilizada para la manufactura de diferentes herramientas, entre ellas un diseño de pequeñas puntas de flecha. Los análisis de procedencia de la obsidiana indican que habría sido obtenida en distintas fuentes de Antofagasta de la Sierra (Flores et al. 2010). Es decir, la circulación de esta materia prima no tendría una restricción particular en el espacio que pueda reflejar algún tipo de limitación en cuanto a su acceso por parte de quienes ocupaban estos poblados protegidos.

La cerámica fina que se asume como de procedencia local es la del tipo Belén, representada por tres formas -tinajas, ollas y pucos- pintadas en negro sobre rojo. Estas vasijas se encuentran en todos los sitios aquí analizados. En cambio, los otros tipos hallados que se consideran foráneos o al menos producto de influencias no locales, como Santa María, Famabalasto Negro Grabado, Sanagasta y en muy pocos casos algunas variantes inkas locales, se encuentran en mucha menor cantidad. Si prestamos atención a la distribución regional de los tipos, podemos identificar ciertas tendencias. Por un lado, más allá de la omnipresencia de la cerámica Belén en el valle, un grupo muy especial de tinajas de este tipo con cuellos muy largos y variaciones de ejecución en las imágenes pintadas es casi exclusivo de los sitios del Sector Norte. Por otra parte, la cerámica Santa María se encuentra en todo el valle, pero su proporción sólo es significativa en los sitios del Sector Norte, particularmente en El Molino, Loma de la Escuela Vieja y Pueblo Viejo de El Eje, además de varias tumbas. En cambio, en el Sector Sur los hallazgos de piezas santamarianas son aislados. Por otra parte, existen dos tipos de pucos que han sido hallados casi exclusivamente en el Sector Norte: uno de ellos corresponde a una variante del tipo Santa María, pintada en negro, crema y rojo, con serpientes modeladas; el otro es un tipo de puco negro sobre rojo con incisiones en la pared externa en los que reconocemos, de manera preliminar, la representación de caparazones de quirquinchos (Iucci 2013).

Habíamos establecido las potenciales relaciones de intervisibilidad para los sitios protegidos, y también se había determinado que estos últimos fueron en su gran mayoría muy probablemente contemporáneos en determinado momento del desarrollo cultural regional. A su vez, también concluimos que los vínculos de visibilidad entre los sitios del Sector Sur eran directos, mientras que en el Sector Norte existía una fragmentación en cuanto a las 
líneas de intervisibilidad, al menos en base a los sitios considerados. Teniendo en cuenta las diferencias en la recurrencia del estilo Santa María en el Sector Norte, cabe preguntarse si tal distribución tiene algo que ver con la distinta configuración de las líneas de intervisibilidad en relación al Sector Sur.

Una propuesta interpretativa para esta cuestión podría sostener que el espacio físico del Valle de Hualfín determinó de alguna manera la configuración de los dos sectores mencionados, y la disposición de los poblados tardíos fue generando dos formas diferentes de vinculación entre los grupos locales. Por un lado, un Sector Sur con poblados comunicados en forma constante visualmente (y seguramente, por redes de caminos), que compartían el uso casi exclusivo de cerámica de tipo Belén, manteniendo un modo de vida más centrado en lo local. Y por el otro, un Sector Norte más disgregado, con poblados relativamente más independientes entre sí y una forma de vida más cosmopolita, con un acceso directo a la puna, sosteniendo relaciones frecuentes con grupos de ese ámbito y de los valles del Cajón y de Yocavil, manufacturando, usando y haciendo circular diferentes alfarerías, entre ellas la cerámica propia de los valles norteños y variantes que sintetizan diferentes rasgos locales $\mathrm{y}$ vecinos.

Concluyendo, a lo largo de este trabajo hemos analizado algunos elementos de las tres dimensiones propuestas que nos han permitido ir reconstruyendo relacionalmente distintos aspectos del paisaje tardío para el Valle de Hualfín. En concordancia con la propuesta teórica inicial, la idea final acerca de una diferenciación entre sectores dentro del valle debe articularse con el marco de la perspectiva del poder como eje principal en la conformación del paisaje. En este sentido, en trabajos anteriores habíamos sostenido que el modo en que fue plasmado el paisaje nos habla de una sociedad sin grandes diferencias en la distribución material y, a la vez, de una época de conflictos que pudieron ser reales o potenciales, generados por diferencias al interior de la misma sociedad local o por enfrentamientos con grupos foráneos que los llevaron a refugiarse en sitios protegidos. Algunas características de la configuración espacial de los sitios sugieren la posibilidad de que ciertos grupos tuvieran al menos el privilegio de ocupar espacios, dentro de los asentamientos conglomerados, en los que existían mayores restricciones para el acceso y circulación (tales como algunos sectores de Loma de los Antiguos, Cerro Colorado, El Molino, Loma de la Escuela Vieja), además de una mayor protección dada por la posesión de más y mejores tecnologías y recursos defensivos (Balesta et al. 2011). La relación entre los mismos grupos locales, pugnando por legitimar liderazgos y sus convivencias con los vecinos debió haber implicado tensiones. A todo esto, la llegada de los inkas al territorio pudo haber potenciado los enfrentamientos. En este contexto, la diferenciación entre los sectores Norte y Sur podría ser un reflejo de distintos grados de integración regional hacia el interior del valle durante el siglo XV (y quizás XVI), a la vez que puede indicar diferentes respuestas socio-políticas en relación a los vínculos con grupos foráneos vecinos, con los inkas o con los mismos grupos locales.

\section{Notas}

1. Desde la "perspectiva del habitar" de Ingold (2000) esta división entre la construcción del espacio y el uso del espacio construido se diluye; sin embargo, la finalidad del análisis consiste en indagar en cómo se desarrollan las prácticas constructivas como parte de la experiencia misma del habitar.

2. En función de las particularidades del registro arqueológico estudiado, nuestra propuesta intenta abordar el análisis del espacio sin un énfasis en lo puramente arquitectónico. Más allá 
de esta elección, existen diversas herramientas teóricas y metodológicas para el análisis de los indicadores arquitectónicos y la forma en que se construye y habita el espacio. Algunos de los aportes clásicos en este sentido son, por ejemplo, los de Hillier y Hanson (1984) y Mañana Borrazás et al. (2002).

3. Este sitio se halló destruido en tal grado que fue imposible identificar un recinto completo. La mala conservación se debe principalmente a la instalación de una antena y una casilla en la cima misma, sobre la propia pirca de un recinto, y el huaqueo con grandes pozos, de más de $1 \mathrm{~m}$ de profundidad y hasta $1 \times 2 \mathrm{~m}$ de lado.

\section{Bibliografía citada}

Arkush, E.

2009 Pukaras de los Collas: Guerra y poder regional en la cuenca norte del Titicaca durante el Período Intermedio Tardío. ANDES Boletín del Centro de Estudios Precolombinos de la Universidad de Varsovia 7: 463-479.

Anschuetz, K.; R.H. Wilshusen y C.L. Scheick

2001 An Archaeology of Landscapes: Perspectives and Directions. Journal of Archaeological Research 9(2): 152-197.

Balesta, B.; N. Zagorodny y F. Wynveldt

2011 La Configuración del Paisaje Belén (Valle de Hualfín, Catamarca). Relaciones de la Sociedad Argentina de Antropología XXXVI: 149-175.

Balesta B. y N. Zagorodny

2010 Aldeas protegidas, conflicto y abandono. Investigaciones arqueológicas en La Ciénaga (Catamarca, Argentina). Al Margen, La Plata.

Bugliani, M.F.

2012 Loma l'ántigo: consideraciones sobre la arquitectura de un poblado tardío en el valle del Cajón (Catamarca, argentina). Comechingonia 16: 71-84.

Cosgrove, D.E.

1984 Social Formation and Symbolic Landscape. Croom Helm, London.

Criado Boado, $\mathrm{F}$.

1991 Construcción social del espacio y reconstrucción arqueológica del paisaje. Boletín de Antropología Americana 24: 5-2

Flores, M.; M. Morosi y F. Wynveldt

2010 Determinación de las materias primas líticas de la Loma de los Antiguos de Azampay (Depto. Belén, Catamarca, Argentina). Revista Werkén 13: 261-274.

Giovannetti, M.; M.C. Páez; G. Cochero; P. Espósito; G. Corrado; J. Spina y F. Franchetti 2010 Sectorización del espacio, cerámica y cronología relativa. Análisis comparativos en un asentamiento agrícola multicomponente (Los Colorados, Catamarca). La arqueometría en Argentina y Latinoamérica (ed. por S. Bertolino, R. Cattáneo y A. Izeta), pp. 55-60. Universidad Nacional de Córdoba, Córdoba. 
González, A.R.

1955 Contextos culturales y cronología relativa en el área central del N. O. argentino (nota preliminar). Anales de Arqueología y Etnología 11: 7-32.

González, A.R. y G.L. Cowgill

1975 Cronología arqueológica del Valle de Hualfín, Pcia. de Catamarca, Argentina. Obtenida mediante el uso de computadoras. Actas del Primer Congreso de Arqueología Argentina, pp. 383-404. Rosario.

González García, F.J.

2009 Between warriors and champions: warfare and social change in the later prehistory of the NW Iberian Peninsula. Oxford Journal of Archaeology 28 (1): 59-76.

Hillier, W. y J. Hanson

1984 The social logic of space. Cambridge University Press, Cambridge.

Ingold, $\mathrm{T}$.

2000 The perception of the environment. Essays in livelihood, dwelling and skill. Routledge. London.

Iucci, M.E.

2013 Producción, uso y circulación de cerámica tardía del Valle deHualfín (Depto. de Belén, Catamarca). Tesis Doctoral. Facultad de Ciencias Naturales y Museo, Universidad Nacional de La Plata.

Jarvis, B.

1998 Postmodern Cartographies: The Geographical Imagination in Contemporary American Culture. St. Martin's Press, New York.

Mañana Borrazás, P.; R. Blanco Rotea y X.M. Ayán Vila

2002 Arqueotectura 1: bases teórico metodológicas para una arqueología de la arquitectura. Tapa. Traballos de Arqueoloxía e Patrimonio 25. Instituto de Investigacións Tecnolóxicas, Universidade de Santiago de Compostela.

Nastri, J.

1997-1998 Patrones de asentamiento prehispánicos tardíos en el sudoeste del valle de Santa María (Noroeste argentino). Relaciones de la Sociedad Argentina de Antropología XXII-XXIII: 247-270.

Lynch, J.

2010 El Ushnu incaico y sus implicancias en la cosmovisión local. El sitio Hualfín Inka, Catamarca. Actas del XVII Congreso Nacional de Arqueología Argentina, Tomo II: 801-806. Mendoza.

Nielsen, A.

2002 Asentamientos, conflicto y cambio social en el Altiplano de Lípez (Potosí, Bolivia). Revista Española de Antropología Americana 32: 179-205.

2007 Armas Significantes: Tramas Culturales, Guerra y Cambio Social en el Sur Andino Prehispánico. Boletín del Museo Chileno de Arte Precolombino 12(1): 9-41.

Patterson, T.

1994. Social Archaeology in Latin America: An Appreciation. American Antiquity 59(3): 531-537. 
Raffino, R.A.

2007 Poblaciones indígenas en Argentina. Urbanismo y proceso social precolombino. Emecé, Buenos Aires.

Raffino, R. A.; R. Iturriza; A. Iácona; A. Capparelli; D. Gobbo; V. Montes y R. Vázquez 1996 Quillay: centro metalúrgico inka en el Noroeste argentino. Tawantinsuyu 2: 59-69.

Rapoport, A.

1978. Aspectos humanos de la forma urbana. Editorial Gustavo Gili, Barcelona.

Rivolta, G. y J. Salazar

2007 Los espacios domésticos y públicos del sitio Los Cardones (valle de Yocavil, prov. de Tucumán). Procesos sociales prehispánicos en el sur andino. La vivienda, la comunidad y el territorio (comp. por A.E. Nielsen, M.C. Rivolta, V. Seldes, M.M. Vásquez y P.H. Mercoli), pp. 123-142. Editorial Brujas, Córdoba.

Sempé, M.C.

1981 Investigaciones arqueológicas en el departamento Belén (Catamarca). Novedades del Museo de La Plata 1(2): 18-19.

1999 La cultura Belén. Actas del XII Congreso Nacional de Arqueología Argentina II: 250-258. La Plata.

Smith, A.T.

2003 The Political Landscape. University of California Press, Los Angeles.

Tarragó, M.

1987 Sociedad y sistema de asentamiento en Yocavil. Cuadernos del INAPL 12: 179-196.

Tuan, Y.

1977 Space and Place: The perspective of Experience. Minneapolis, University of Minnesota Press.

Weiser W. y F. Wolters

1923-26 Cuadernos y libretas de la colección Benjamín Muñiz Barreto. Departamento Científico de Arqueología, Museo de La Plata. Manuscrito inédito.

Wynveldt, F.

2009 La Loma de los Antiguos de Azampay: un sitio defensivo del Valle de Hualfín (Catamarca, Argentina). Sociedad Argentina de Antropología, Buenos Aires.

Wynveldt F. y M.E. Iucci

2009 La cerámica Belén y su definición a través de la historia de la arqueología del NOA. Relaciones de la Sociedad Argentina de Antropología XXXIV: 275-296.

2013. La cronología Belén en el Norte del Valle de Hualfín: viejos problemas, nuevas perspectivas. Revista Arqueología 19 (1): 187-195.

Zedeño, M.N.

2000 On What People Make of Places. A Behavioral Cartography. Social Theory in Archaeology (ed. por M. Schiffer), pp. 97-111. University of Utah Press, Salt Lake City. 
